\title{
Child Psychiatric Services in India
}

L. B. BARTlet, Consultant Psychiatrist, Paediatric Department, Southampton General Hospital, Southampton; Visiting Psychiatrist, King George's Medical College, Lucknow, India

The evolution of general psychiatry in India has for many years followed the British pattern, stage by stage. ${ }^{1}$ Child psychiatry has followed much the same path and British influences are much in evidence.

Early development. One of the first psychiatrists to take a special interest in children was Austrian. In the fifties Dr Erna Hoch developed a service for children in the Methodist Hospital in Lucknow. She carefully documented her experiences with Indian children and their families, giving due attention to cultural and religious factors. She brought together her observations in a work entitled Indian Children in a Psychiatric Playground. This work did not receive the attention it deserved; the title did not help, but the main reason may have been that it was a decade ahead of its time.

Child guidance clinics. In America and Britain the foundations of child psychiatry were laid in the child guidance movement. Between 1935 and 1960, nationwide networks of multidisciplinary staffed clinics were established. Initially, these clinics (which were often small and parttime) were in the hands of social workers, psychologists and general psychiatrists, all of whom were interested in children's work but few of whom had received any formal education in child psychiatry.

A similar sequence of developments occurred in India in the period 1960-80. The Indian clinics set up then were often the offshoots of teaching hospital departments of psychiatry and owed much to the enthusiasm of particular psychiatrists, very few of whom had any training in children's work. A few clinics were grafted onto other children's facilities such as community projects and children's homes. Sixteen such clinics were operating in Bombay in 1979. Most cities, however, rarely have more than one clinic-many have none.

These clinics often operate under very adverse circumstances: shortage of staff, accommodation, equipment, and administrative back-up. Whilst immediate neighbourhood links are often good, communications with schools and other agencies are poor by Western standards. Isolation from other workers in the child guidance field is another problem. However, there is no disputing the role which these clinics play in promulgating the needs and rights of children.

Basic services and child mental health. WHO guidelines issued in 1978 encouraged developing countries to provide basic child mental health services within the framework of existing child welfare and child health programmes. Progress in India, however, as in most other countries, has been slow. Manuals for primary health workers have been developed. Primary health centre medical officers, overwhelmed by a multitude of tasks, have accorded a low priority to child mental health. Hopes of grafting child mental health programmes on to the Anganwadi and Integrated Child Development Schemes have not so far been fulfilled. An idea currently in favour is the provision of training courses for general psychiatrists and paediatricians already serving communities.

Child psychiatric facilities. WHO also advocated the establishment of 'centres of excellence' for child mental health-one such centre for approximately 25 million population, such centres having educational and clinical components. There are already some centres in India that merit this description.

Attached to the National Postgraduate Institute in Bangalore (NIMHANS) is a flourishing Department of Child Psychiatry. It embraces a very busy out-patient service and a residential unit which provides for parents as well as children. The Department works in close collaboration with the mental handicap team. Trainee psychiatrists are required to spend three months full time working with children and families. Staffing is multidisciplinary, psychologists playing a particularly valuable part. The consultant in charge has an academic lecturer's post within the Institute.

In the large Department of Psychiatry at King George's Medical College, Lucknow, led by Professor B. B. Sethi, there is a strong interest in child psychiatry. The children's unit is separately housed and has its own garden and grounds. The team is directed by two consultants with Reader and Lecturer status respectively. There is a longstanding link with the child psychiatric service in Southampton, out of which an early stimulation programme for mentally handicapped children has emerged. The unit has links with special schools, children's homes, rehabilitation centres and a nearby paediatric department.

In the western city of Ahmedabad is the BM Institute, a charitable foundation which has links with the Tavistock Clinic. Psychodynamic in its philosophy, it provides a valuable dimension in the field of child and family mental health. Interprofessional relationships are sound and nonhierarchical and the atmosphere is reminiscent of some of the bigger and better services in Britain.

Clinical considerations. Little as yet is known about the prevalence of child psychiatric disorders. Attention is focusing on patterns of referral and the Indian Council of Medical Research has organised a four-centre study of 
children seen at four major departments in different parts of India. Clinical experience (which is all there is to go on, at present) suggests that the same categories of disorder are seen as in the West-though in different proportions.

Mental retardation is the largest referral category, constituting about half of the total in many clinics. The burden of mental retardation falls heavily on Indian psychiatrists, especially if they have a particular interest in children. Paediatricians, pressed by the needs of acutely ill children, have little time to give to this group. Morley in his important book Paediatric Priorities in the Developing World refers to neither handicap nor subnormality. ${ }^{2}$ Consequently the psychiatric clinics take the strain. Assessment procedures are improving. Concomitant physical illnesses are treated, e.g. epilepsy. But existing services are not even scratching the surface of the mental handicap problem. Taking a prevalence rate of $3 \%$ and assuming a third of the population is under 15 (WHO estimate) there are seven million retarded children in India. Moderately, as opposed to severely, handicapped children seem to swell clinic populations. This might be because severely damaged children die at birth or later through vulnerability to intercurrent infections. Neurological damage is common, as one might expect against a background of poor perinatal and infant care, malnutrition and infections of both the gastrointestinal and central nervous systems.

Psychoses or conditions akin to psychoses appear very frequently in child psychiatric contexts. In Lucknow in 1984 about $10 \%$ of in-patient adolescents were suffering from such conditions. This contrasts strikingly with the UK scene where adolescent psychosis is rare. The Isle of Wight Survey included 2000 adolescents and only one was classified psychotic. $^{3}$ Not all manifest straightforward schizophrenic or affective states. Diagnosis can be difficult, where the disturbances are of sudden onset and behaviourally florid. Oneroid features are occasionally noted. Some of the young patients have passed through other healing hands (general practitioners, gurus, traditional healers) before reaching the specialist facility. Treatments en route complicate diagnosis. Poor laboratory resources limit the confirmation of physical illness (to which there are often pointers). Mental state assessments are difficult to carry out as patient co-operation is poor. Many of these disorders respond quickly to treatment. They would appear to conform to the picture of the 'transient psychosis' described in adults in developing countries.

Psychosomatic conditions are common. Behind the clinical manifestations lie a variety of diagnoses-psychosis, depression, anxiety, hysteria, physical illness associated with stress, and iatrogenic illness (such as phenothiazine overdosage).

Behaviour disorders are not seen in large numbers. It would seem that in India child conduct disturbance is not regarded as a psychiatric matter. Such children as are seen often come from middle-class backgrounds. Delinquency is seldom a reason for seeking psychiatric attention though some remand homes have some psychiatric cover-in Bombay for example.
Emotional disorders occur and these appear in child psychiatric clinics. As in China, anorexia nervosa is rare-a reflection perhaps of the differing adolescent body image ideals. ${ }^{4}$

Developmental delay does not appear to worry Indian parents very much except where speech and education are concerned. Most of the rare syndromes of childhood such as elective mutism and Gilles de la Tourette's syndrome have been reported in the Indian literature.

Treatment. Remarks about treatment need to be prefaced by a brief consideration of hospital practice and patient expectation in India. Patients and parents still look to doctors (including psychiatrists) to provide 'medical' treatments even when the problem is behavioural or developmental. Developmental conditions are poorly comprehended, and this leads to unrealistic and often intolerant attitudes to educational and mental retardation. Parents talk happily to professionals but do not conceptualise the 'talking' is as important in treatment terms. They often regard the hospital visit as a 'once and for all' exercise. Out-patient appointments or regular visits are not properly understood except by the upper classes. This clearly limits the application of psychotherapy and behaviour therapy and, for that matter, any treatment that necessitates more than one or two visits. It fits, too, with the fact that treatment in general is less well developed than assessments.

Psychotherapy is not extensively used. The interest is there but clinics are so stretched the time is not there. Parent counselling is available in units that have the good fortune to have a psychiatric social worker. Although Indian children are customarily well supported by their families, family therapy is not in the front line. The strong, traditional structure of the Indian family - the joint family system-is likely to offer more resistance to change than the Western nuclear family.

Behaviour therapy is not extensively used. This may be a reflection of the small number of psychologists working in the services, poor parental understanding, and the tendency, cited above, to look for medical answers.

Drugs are not used excessively in the specialist departments but they are outside, particularly by general practitioners. Parents expect psychiatrists to prescribe and if they do not do so they may be perceived as being neglectful. This pattern contrasts with the contemporary British scene where psychiatrists may incur parental displeasure by 'pill-pushing'. Finally, there is the problem of maintenance therapies, e.g. anticonvulsants. These are often abandoned by parents who do not follow the principles involved.

The education system. India's state schools are grossly underfinanced. Many schools amount to little more than open air meeting places. Primary teachers are inadequately trained, face classes of 60 children, receive low wages and have little status in the community. Private education is of varying quality, though the best is very good. Teachers appear to know little about psychology and mental health and many see their task as the input of facts that are 
examination-related. Educational psychologists are almost as rare as child psychiatrists.

Though rural and urban poor are still somewhat indifferent to schooling, the middle classes display an anxious preoccupation. Parents in these social levels often see academic success as the only escape route from the stresses they themselves face. So much store is put by education. There is a national obsession with examinations and the pressures fall on children at a frighteningly early age. The writer heard of a 3 year-old failing a school entrance examination because he gave an incorrect answer to the question "Where is Allah?" The educational pressures persist through the years to the realms of higher education. Paediatricians and general practitioners know of the strain on children and adolescents as they see the psychosomatic consequences. The consequences may sometimes be fatal and a very high suicide rate in 14 year olds and under in the Bangalore area has been reported. 5 There are echoes here of the Brain Fag Syndrome seen in Africa. Parents and teachers, perhaps because they are so caught up with examination results, do not have the necessary awareness, so there is a tremendous need for mental health programmes to penetrate the school and college system. There have been some pioneering moves in this direction-in Bangalore for example, where a child psychiatrist and a psychologist ran counselling courses for secondary school teachers. ${ }^{6}$ The scope for health education programmes is enormous.

\section{Conclusion}

Child psychiatry is beginning to take shape in India. The pattern of services is likely to differ substantially from Western models. Child mental health will be part and parcel of the Child Health Programme; general psychiatrists will attend to the bulk of serious child psychiatric problems; and the few psychiatrists fully trained in children's work will operate from regional 'centres of excellence' which will be educational as well as clinical resource centres.

\section{REFERENCES}

Neki, J. S. (1973) Psychiatry in South East Asia. British Journal of Psychiatry, 123, 257-269.

Morley, D. (1973) Paediatric Priorities in the Developing World. London: Butterworths.

Graham, P. \& Rutrer, M. (1973) Psychiatric disorder in the adolescent: a follow-up study. Proceedings of the Royal Society of Medicine, 66, 1226-1229.

Parry-Jones, W. L. (1986) Psychiatry in the People's Republic of China. British Journal of Psychiatry, 148, 632-641.

Sathyavath, K. (1975) Suicide among children in Bangalore. Indian Journal of Psychiatry, 42, 149-157.

CARIAPPA, L. \& KAPUR, M. (1978) Evaluation of training programme for school teachers in student counselling. Indian Journal of Psychiatry, 20, 289-291.

A full list of references is available from the author on request.

\section{AUTP Postgraduate Training in Behavioural Psychotherapy 1987-1988}

The Association of University Teachers of Psychiatry (AUTP) with the Institute of Psychiatry runs an annual course in behavioural psychotherapy. The course will begin with a two-day workshop on Wednesday, 30 September and Thursday, 1 October, 1987. This will include the following components: Theoretical background, demonstration of treatments and participant practice. After the workshop participants will be asked to undertake behavioural treatment of their own patients in their own centres, and later also to supervise other trainees. Participants will be supervised in small groups at monthly intervals in half-day sessions over the following academic year. During the twoday workshop and throughout the course eminent guest speakers from round the UK will run seminars on behav- ioural treatment in acute and chronic disorders in adults, the elderly, children, mental handicap, and liaison psychiatry. A certificate will be awarded to those completing the course.

The course is organised on lines which qualify for local funding assistance under Study Leave Regulations of the British Postgraduate Medical Federation. Cost of the combined workshop, monthly supervision and reading materials over the following academic year is $£ 285$. Applicants should write, stating their qualifications and current appointment, to Professor Isaac Marks at the Institute of Psychiatry, De Crespigny Park, Denmark Hill, London, SE5 8AF, where the course will be held.

\section{Monthly Consultation Seminars}

Monthly Consultation Seminars are to be held at the Tavistock Clinic starting in October 1987. The course is designed to meet the needs of senior practitioners in the helping professions who wish to expand their consultative skills and who live and work out of London. Further infor- mation and application form can be obtained from The Training Administrator, The Tavistock Clinic, 120 Belsize Lane, London NW3 5BA (telephone 014357111 , extension 313 or 469$)$. 